Research Article

\title{
Group 2 Innate Lymphoid Cells Are Involved in Skewed Type 2 Immunity of Gastric Diseases Induced by Helicobacter pylori Infection
}

\author{
Rong Li, ${ }^{1,2}$ Xiao-xia Jiang, ${ }^{1,2,3}$ Lin-fang Zhang, ${ }^{1,2}$ Xiao-ming Liu, ${ }^{1,2}$ Ting-zi Hu, ${ }^{1,2}$ \\ Xiu-juan Xia, ${ }^{1,2}$ Ming Li, ${ }^{1,2}$ and Can-xia $\mathrm{Xu}^{1,2}$ \\ ${ }^{1}$ Department of Gastroenterology, Third Xiangya Hospital of Central South University, Changsha, China \\ ${ }^{2}$ Hunan Key Laboratory of Nonresolving Inflammation and Cancer, Changsha, China \\ ${ }^{3}$ Department of Gastroenterology, The Central Hospital of Yongzhou, Yongzhou, China \\ Correspondence should be addressed to Can-xia Xu; xucanxia2000@163.com
}

Received 9 May 2017; Revised 23 July 2017; Accepted 7 August 2017; Published 12 September 2017

Academic Editor: Ulrich Eisel

Copyright ( 2017 Rong Li et al. This is an open access article distributed under the Creative Commons Attribution License, which permits unrestricted use, distribution, and reproduction in any medium, provided the original work is properly cited.

H. pylori induces a complicated local and systematic immune response and contributes to the carcinogenesis of gastric cancer. A primary type 1 immune response is evoked by $H$. pylori since its occurrence. However, it is not unusual that an inhibitory immunity is dominant in $H$. pylori-associated diseases, which are promoted by the formation of immunosuppressive microenvironment. But whether group 2 innate lymphoid cells (ILC2s) plays a critical role in $H$. pylori-induced skewed type 2 immunity is still unclear. In the present study, firstly, we confirmed that type 1 immunity was inhibited and type 2 immunity were undisturbed or promoted after $H$. pylori infection in vitro and in vivo. Secondly, GATA-3 was firstly found to be increased in the interstitial lymphocytes from $H$. pylori-associated gastric cancer, among them, Lin-GATA- $3^{+}$cells and $\mathrm{Lin}^{+}$GATA $-3^{+}$cells were also found to be enhanced, which indicated an important role for ILC2s in $H$. pylori infection. More importantly, ILC2s were found to be increased after $H$. pylori infection in clinical patients and animal models. In conclusion, our results indicated that ILC2-mediated innate immune response might play a potential role in dominant type 2 phenotype and immunosuppressive microenvironment in $H$. pylori infection.

\section{Introduction}

Helicobacter pylori (H. pylori) is a small, curved gramnegative bacterium with high motility; it colonizes the epithelium of human beings' stomach. According to epidemiological surveys, $H$. pylori has infected half of the world's population and has been proved to be the type I causative agent of gastric adenocarcinoma [1], which is the second most common diagnosed cancer and second most common cause of cancer-related deaths worldwide [2]. Gastric cancer is commonly classified into two subtypes based on its histological architecture, including the intestinal type and the diffuse type. Both subtypes have been tightly associated with $H$. pylori, and the chronic inflammation elicited by $H$. pylori very likely offers the setting in which gastric cancer initiation can occur [3]. Even so, only few individuals with $H$. pylori ${ }^{+}$ population experience a discomfort of the stomach caused by its colonization, and there are nearly $1-2 \%$ of infected individuals developing gastric adenocarcinoma eventually. However, no single universal explanation has yet been found to hold true across all populations studied, and it is likely that a combination of multiple factors determines the infection-related outcome.

The immune system including cellular immunity and humoral immunity will be activated when the defense barrier is destroyed by microorganisms. In most cases, the type of specific immunity induced is of key importance for protection. However, under certain circumstances, an improper response can even promote the induction of immunopathology $[4,5]$. As a common sponsor for chronic gastric 
inflammation, persistent survival of $H$. pylori is always accompanied with activated local and systemic immune response, which has been derived from results of plenty of independent studies [6,7]. Inflammation with $H$. pylori infection has widely been suggested to trigger gastric carcinogenesis through "inflammation-carcinoma chain." H. pylori possesses an important ability on recruitment and differentiation of lymphoid cells in the stomach.

Neutrophils, macrophages, dendritic cells, and T cells are usually effector cells caused by $H$. pylori infection. Neutrophils are suggested to contribute to the clearance of $H$. pylori at least partly by recruiting more effective cells to the gastric mucosal epithelium [3]. T cells play a crucial role in the outcome of $H$. pylori involvement [8]. Most T cells in the resting state, named as Th0, show neither polarized phenotype but hold the potency to differentiate into type 1 or type 2 effective T helper cells (Th1 or Th2), which represent a predominant type 1 or type 2 cytokines, respectively. Both bacterial virulence and host genetic factors fluctuate the Th1 or Th2 differentiation mainly by promoting the leader cytokines in the microenvironment. IL-12, IL-18, and IFNs are powerful stimuli for Th1 development, whereas IL-4 promotes Th2.

During the development of $H$. pylori infection-associated pathologies, the levels of IL-12 and IL-2 gradually decreased, but IL-10 increased, which indicated some transformation in the patterns of cellular to humoral immunity. It has been demonstrated that a polarized type 2 immunity, but not type 1 immune response, is more frequently found in the chronic gastritis, precancerous lesions, and gastric adenocarcinoma caused by $H$. pylori infection [9]. An increasing tendency of IL-4 expression accompanies with the progression of gastric lesions, leading to a gradual decrease in Th1/Th2 ratio in $\mathrm{CagA}^{+} H$. pylori-infected patients $[9,10]$. Moreover, it indicates that $H$. pylori stimulates a type 2 inflammatory response, which constitutes the significant character of its immunopathogenesis. These not only result in persistent survival of the bacterial pathogen that initiates the carcinoma but also promote a microenvironment for immune escape.

The highly complex host responses are involved in the coordination of innate and adaptive immune cell types, and the immunity to $H$. pylori infection is not exceptional. Not the adaptive immune cells, but the innate immune cells, as the important part of defending the barrier, react promptly to the alien invader at an early stage, and they evoke a timely defense. Innate lymphoid cells (ILCs), newly identified lymphocyte subsets, have thus attracted interests of many researchers in the fields of infectious disease [11]. ILCs are distributed in a wide variety of epithelial compartments and act as an intermediate position between acquired immune cells and bone marrow cells. Based on their cytokine production patterns that correspond to the T helper cell subsets Th1, Th2, and Th17, ILCs are commonly classified into three groups: ILC1, ILC2, and ILC3, respectively [11].

GATA-3, a critical regulator for type 2 immunities including ILC2s and Th2 cells, has been firstly found upregulated in $H$. pylori-associated gastric cancer from our previous differential screening of transcription factor expression [12]. The zinc-finger transcription factor, GATA-3, has received much attention as a master regulator of Th2 cell differentiation. More recently, apart from Th2 cells, ILC2, an important member of innate immunity, has been demonstrated to be another vital source of type 2 cytokines. What is more important is that GATA-3 was shown to contribute to type 2 immunity through regulation of ILC2 development and function [13, 14]. ILC2s potentiate and synergize memory Th2 cell responses in many ways $[15,16]$. Moreover, it has been demonstrated that ILC2s were necessary for Th2 cell differentiation and maintenance $[17,18]$. Therefore, a potential role of ILC2s in dominant type 2 immunity caused by $H$. pylori infection has attracted our interest.

In this study, by using clinical samples (plasmas and PBMCs from healthy volunteers (normal), individuals with chronic atrophic gastritis (CAG), and individuals with gastric adenocarcinoma (GC)) and establishing an $H$. pylori infection model in vivo and in vitro, we have demonstrated that immune response showed a gradual predominant trend for type 2 immunity in the progression of $H$. pylori-induced pathologies, when compared to a decreasing trend for Th1. GATA-3 expression has been firstly found to increase in lymphocytes derived from $\mathrm{H}$. pylori ${ }^{+}$gastric cancerous tissues. An experimental model of $H$. pylori infection established in vitro proved that $H$. pylori infection induced a leading type 2 immune response by enhancing the transcription factor GATA-3 and an increased population of $\mathrm{Lin}^{-} \mathrm{GATA}-3^{+}$. The latter indicated a vital phenotype for ILC2s. Moreover, the lymphocytes from clinical patients and an $H$. pyloriinfected animal model have revealed that an incremental ILC2s might play a key role in the immune response to H. pylori infection.

\section{Materials and Methods}

2.1. Clinical Tissue Preparation. Clinical specimens were collected from 120 patients and healthy volunteers who underwent gastroscopy screening and diagnosis at the Third Xiangya Hospital of Central South University between May 2015 and February 2017. All informed consents were acquired from patients before sampling. To conduct cytokine chip hybridization and further detection, specimens and blood samples from $H$. pylori-positive ${ }^{+}$or $H$. pylori-negative $(-)$ chronic atrophic gastritis (CAG) and gastric cancer (GC) individuals were collected; moreover, normal samples offered by healthy volunteers were used as the control.

2.2. ELISA (Enzyme-Linked Immunosorbent Assay) for Cytokines. Plasma levels of IL-4, IL-5, IL-13, and IFN- $\gamma$ (Shanghai ExCell Biology, China) were measured by the ELISA kit following the manufacturer's protocols. Concentration was calculated according to the standard curve.

2.3. PBMC (Peripheral Blood Mononuclear Cell) Isolation. Heparinized peripheral blood diluted with 1:1 phosphatebuffered saline (PBS) was layered over an equal volume of Ficoll and centrifuged as per the manufacturer's instructions. 
TABLE 1: Gene primer sequences were used for RT-PCR analysis.

\begin{tabular}{|c|c|c|}
\hline & Forward primers $\left(5^{\prime}-3^{\prime}\right)$ & Reverse primers $\left(3^{\prime}-5^{\prime}\right)$ \\
\hline Human IL-4 & ТСТСАССТСССААСТGСТТС & TGTCTGTTACGGTCAACTCG \\
\hline Human IL-5 & ATCTTTCAGGGAATAGGCACA & TTGCAGGTAGTCTAGGAATTGGT \\
\hline Human IL-13 & CACTTGCCTTGGCGGCTTTG & CCTTCTGGTTCTGGGTGATG \\
\hline Human IFN- $\gamma$ & ACTTCTTTGGCTTAATTCTC & AGTTCCATTATCCGCTACAT \\
\hline Human GATA-3 & GGAGTGTGTGAACTGTGGGG & TTCGCTTGGGCTTAATGAGG \\
\hline Human GAPDH & GAGCCACATCGCTCAGACAC & CATGTAGTTGAGGTCAATGAAG \\
\hline Mouse GATA-3 & GACCCGAAACCGGAAGATGT & TTTTCCACGTACTGCGCG \\
\hline Mouse $\beta$-actin & CGTGCGTGACATCAAAGAGAA & AAGCTCGTCCTCTACCGG \\
\hline
\end{tabular}

Mononuclear cells were collected from the interface between Ficoll and plasma. The collected PBMCs were washed by PBS for 3 times for the next intervention.

2.4. Quantitative Real-Time PCR ( $q R T-P C R)$. Expressions of IL-4, IL-5, IL-13, IFN- $\gamma$, and GATA-3 genes were analyzed by qRT-PCR. Briefly, total RNA was extracted, respectively, from the above-mentioned samples by using the RNeasy Mini kit, and total RNA was reversely transcribed into cDNA using random primers and M-MLV reverse transcriptase (Qiagen) according to the manufacturer's recommendations. RT-PCR was built by using the iScript ${ }^{\mathrm{TM}}$ two-step RT-PCR kit with SYBR Green (Invitrogen) and the targeting gene primers. All gene primer sequences are shown in Table 1. PCR was performed in triplicate on the real-time PCR detection system with the following cycling parameters: $95^{\circ} \mathrm{C}$ ( $1 \mathrm{~min}), 40$ cycles of $95^{\circ} \mathrm{C}(15 \mathrm{~s})$, and $60^{\circ} \mathrm{C}(60 \mathrm{~s})$. The qRTPCR data were quantified by $2^{-\triangle \triangle \mathrm{Ct}}$.

2.5. Immunohistochemistry Staining (IHC). The rapid PV two-step staining method with the following specifications was used: paraffin slice thickness is $4 \mu \mathrm{m}$; slices were grilled at $65^{\circ} \mathrm{C}$ for $60 \mathrm{~min}$ and then dewaxed in xylene and rehydrated in an increasing diluted ethanol series; hightemperature antigen retrieval was performed via a microwave in $0.1 \mathrm{M}$ citrate solution ( $\mathrm{pH} 6.0$ ) for $10 \mathrm{~min}$; slices were incubated with $3 \% \mathrm{H}_{2} \mathrm{O}_{2}$ at room temperature for $20 \mathrm{~min}$, with goat serum at room temperature for $20 \mathrm{~min}$, and with antiGATA-3 rabbit polyclonal antibody (Cell Signaling Technology, USA; diluted $1: 200)$ at $4^{\circ} \mathrm{C}$ overnight; slices were rewarmed in the next day and then incubated with the second anti-rabbit antibody at room temperature for $20 \mathrm{~min}$, after being washed with PBS; DAB coloration was performed; hematoxylin were mounted; and microscopic examination was conducted.

2.6. Tumor-Infiltrating Lymphocyte Preparation. Tumor tissues were taken from the center of the cancer immediately after surgical removal and histologic confirmation. For preparation of single cell suspensions, tumor samples were mechanically dissected and incubated with $1 \%$ type IV collagenase supplemented with $100 \mathrm{U} / \mathrm{ml}$ penicillin and $100 \mathrm{mg} /$ $\mathrm{ml}$ streptomycin at $37^{\circ} \mathrm{C}$ for 30 minutes. The cell suspension was passed through a sterile $40 \mu \mathrm{m}$ nylon filter (BD Falcon, Heidelberg, Germany) and then was layered over an equal volume of Ficoll and centrifuged as per the manufacturer's instructions. Mononuclear cells were collected and suspended in PBS/culture medium.

2.7. Cell Culture and Coculture System. The human gastric epithelial cell GES-1 or freshly isolated PBMCs were grown in RPMI-1640 (Gibco/Life Technologies, Grand Island, NY) plus medium supplemented with $10 \%$ (vol/vol) heatinactivated fetal bovine serum (Sijiqing, China), $100 \mathrm{U} / \mathrm{ml}$ penicillin, and $100 \mathrm{mg} / \mathrm{ml}$ streptomycin in a controlled humidified atmosphere in an incubator containing 5\% $\mathrm{CO}_{2}$ and were passaged with $0.25 \%$ trypsin when necessary.

A transwell chamber (pore size $=3 \mu \mathrm{m}$; Corning Inc.) was used for the coculture system. $1 \times 10^{4} \mathrm{GES}-1$ was planted on the upper chamber of cell culture inserts overnight; then, live $H$. pylori or $H$. pylori lysates (ultrasonic crushing of $H$. pylori) were added into the upper chambers and $1 \times 10^{6}$ freshly isolated PBMCs were separately seeded into the lower culture plates; these cells were cocultured. After coculture for 24 hours, PBMCs, GES-1, and supernatants from the lower chamber were collected for further analysis.

2.8. Bacterial Culture. The H. pylori strains SS1 (Western type) and ATCC 43504 were donated by Professor Yong Xie (Department of Gastroenterology, First Affiliated Hospital of Nanchang University, Jiangxi, China) and maintained in our laboratory. East Asian-type $\mathrm{CagA}^{+}$H. pylori and $\mathrm{CagA}^{-} H$. pylori were isolated from gastric ulcer patients' specimens during gastroscopy, respectively. They were grown on a Columbia blood agar plate supplemented with antibiotics $(10 \mathrm{mg} / \mathrm{l}$ vancomycin, $5 \mathrm{mg} / \mathrm{l}$ cefsulodin, $5 \mathrm{mg} / \mathrm{l}$ amphotericin, and $5 \mathrm{mg} / \mathrm{l}$ trimethoprim) and $10 \%$ sheep blood (Bianzhen Biotech, Nanjing, China) at $37^{\circ} \mathrm{C}$ in microaerophilic conditions $\left(5 \% \mathrm{O}_{2}, 10 \% \mathrm{CO}_{2}\right.$, and $\left.85 \% \mathrm{~N}_{2}\right)$ for $3-4$ days. Then, the $H$. pylori, which was in the early log phase with good motility and activity for subculture or intervention, was harvested and resuspended in PBS. H. pylori concentration was estimated by measuring the $\mathrm{OD}_{600 \mathrm{~nm}}$, where $\mathrm{OD}_{600 \mathrm{~nm}}$ corresponds to about $2 \times 10^{8} \mathrm{CFU}$ (colony-forming unit) $/ \mathrm{ml}$. H. pylori was added to GES-1 at a MOI (multiplicity of infection) $=100,200$, or 400 .

2.9. Animal Model. Twenty 4-6-week-old male C57BL/6 mice were purchased from the Department of Laboratory Animal, Third Xiangya Hospital of Central South University 


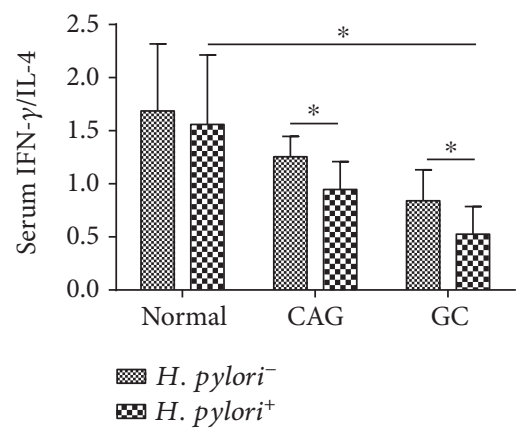

(a)

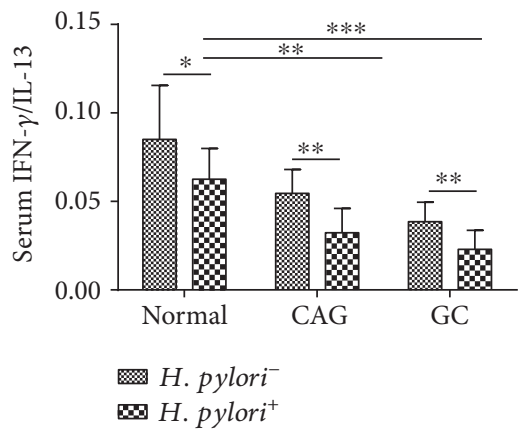

(c)

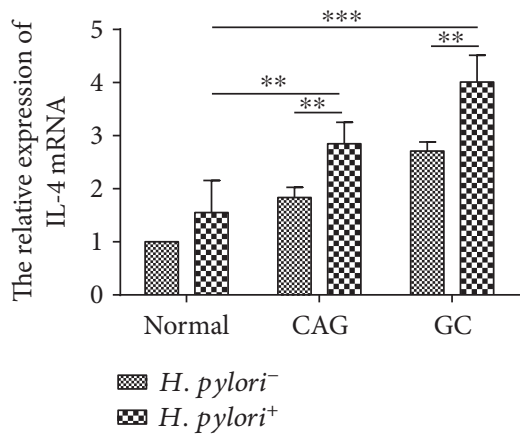

(e)

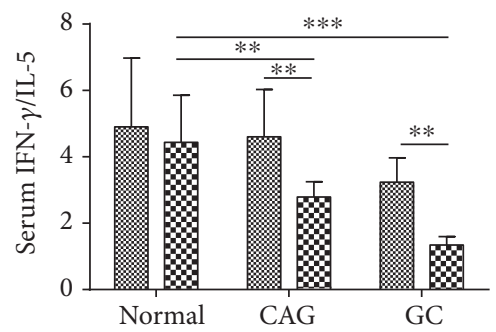

H. pylori ${ }^{-}$

H. pylori ${ }^{+}$

(b)

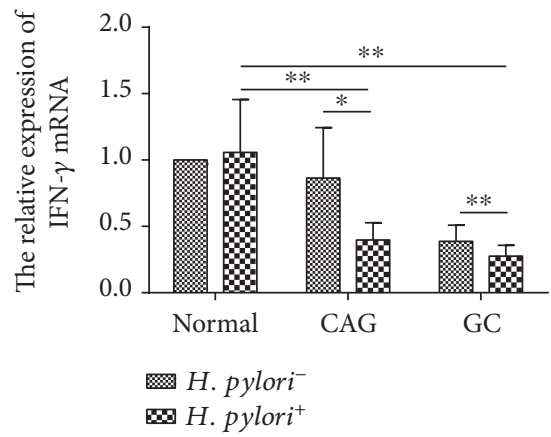

(d)

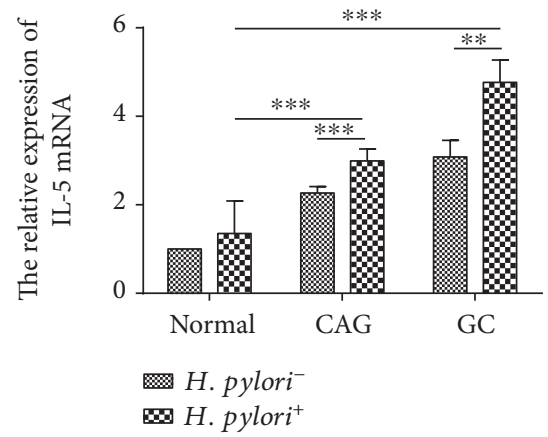

(f)

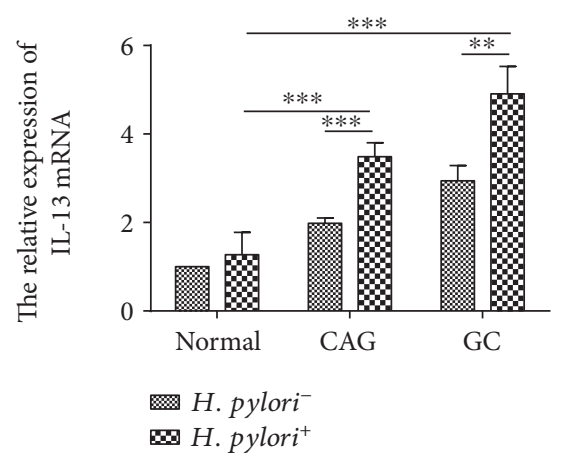

(g)

FIGURE 1: The imbalance of type 1 cytokine/type 2 cytokine expression was found in $H$. pylori-associated gastric diseases. The ratio of plasma IFN- $\gamma /$ IL-4 (a), IFN- $\gamma /$ IL-5 (b), IFN- $\gamma /$ IL-13 (c) decreased along with the progression of gastric cancer, including chronic atrophic gastritis (CAG) and gastric cancer (GC). Moreover, H. pylori infection exacerbated this trend. IFN- $\gamma$ (d) mRNA decreased, but IL-4 (e), IL-5 (f), and IL-13 (g) mRNA expression increased in PBMCs derived from the $H$. pylori-infected individuals along the gastric cancer progression, when compared to those without $H$. pylori infection. ${ }^{*} p<0.05,{ }^{* *} p<0.01$, and ${ }^{* * *} p<0.001$. 


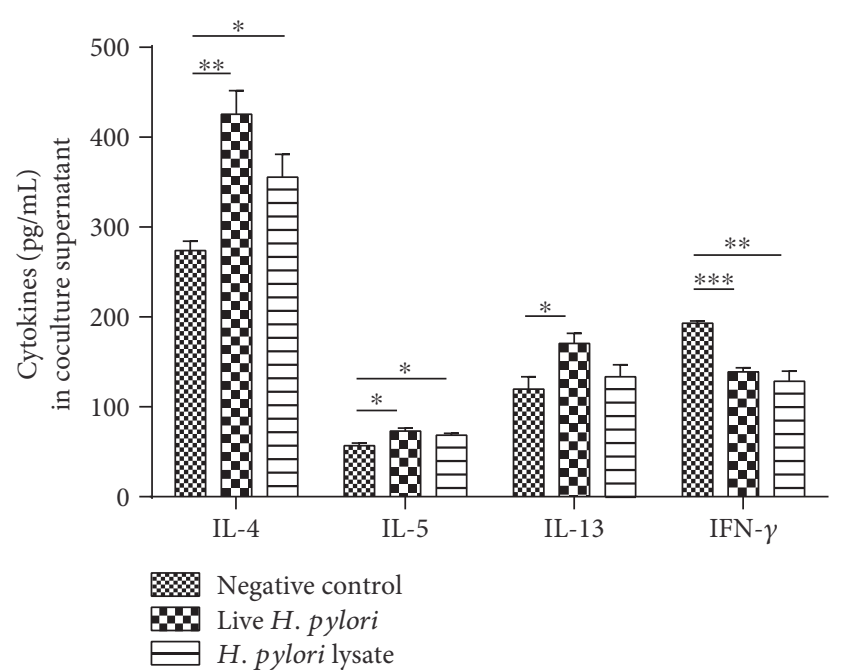

(a)

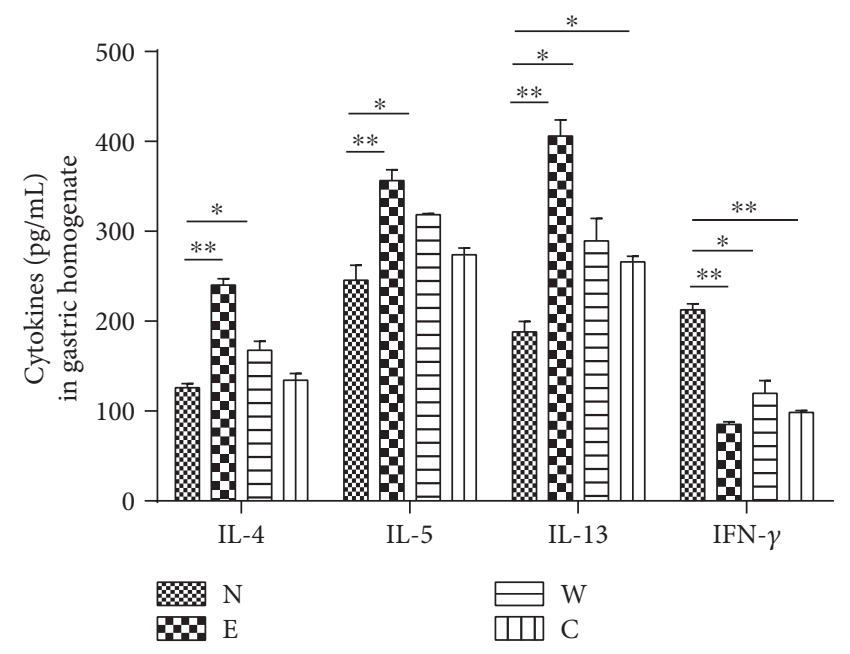

(b)

FIGURE 2: The imbalance of type 1 cytokine/type 2 cytokine expression was also introduced by H. pylori infection in vitro and in vivo. (a) After coculture for 48 hours, the concentration of IL-4, IL-5, and IL-13 in supernatants was increased in the $H$. pylori intervention group, while the expressions of IFN- $\gamma$ reduced. (b) After successful establishment of an $H$. pylori-infected model, the concentration of IL-4, IL-5, and IL-13 was enhanced in gastric homogenate from mice treated with $H$. pylori strains; however, IFN- $\gamma$ in plasma was inhibited, when compared to that in the normal group. Moreover, the East Asian type evoked the most significant change. ${ }^{*} p<0.05,{ }^{* *} p<0.01$, and ${ }^{* * *} p<0.001$.

(Changsha, China); they were allocated into 4 groups randomly: the East Asian group (E), Western group (W), CagA ${ }^{-}$ group (C), and normal control group (N). After fasting for 24 hours, these mice were inoculated with East Asian-type $\mathrm{CagA}^{+}$H. pylori, Western-type CagA ${ }^{+} H$. pylori, and CagA ${ }^{-}$ $H$. pylori by intragastric gavages (once every two days and lasted for a week), respectively. The normal controls were carried out with saline gavages. All mice were dieted with the same food and sterile water. The mice were sacrificed 6 weeks after intragastric gavages. Rapid urease test (RUT) and pathological biopsy were employed for detecting $H$. pylori infection. Splenocytes were obtained for preparation of lymphocyte suspensions. The gastric antrum tissues were collected and maintained in liquid nitrogen immediately for further histological detection and gastric tissue homogenate preparation. Medical ethics protocol was approved by the IRB of the Third Xiangya Hospital of Central South University.

2.10. Flow Cytometry Analysis. After the cleavage of red blood cells by Red Blood Cell Lysis Buffer (BD Pharmingen ${ }^{\mathrm{TM}}$, San Jose, CA, USA), lymphocyte suspensions from splenocytes were obtained for further analysis. For GATA-3 analysis, PBMCs, TILs, or splenocytes were collected and washed in PBS; then, the cells were fixed, permeabilized, and stained at $4^{\circ} \mathrm{C}$ with PE-conjugated GATA-3 as above before analysis. For ILC2 analysis, cells were labelled with antibodies to lineage markers (FITC-conjugated CD3, CD14, CD16, CD19, CD56, and FceRIa) and antibodies to CD127 and CRTH2 (BD Pharmingen, San Diego, CA, USA) for $30 \mathrm{~min}$ at $4^{\circ} \mathrm{C}$. Isotype control antibodies were used to determine positive cells. After staining, cells were washed or fixed with $1 \%$ paraformaldehyde and analyzed by using a FACS Canto II system (BD, Franklin Lakes, NJ, USA).
2.11. Statistical Analyses. Data were presented as the means \pm standard deviations. Statistics were performed by using paired and unpaired Student $t$-tests as appropriate for each set of experimental conditions. $p<0.05$ was considered statistically significant.

\section{Result}

3.1. A Skewed Type 2 Immune Response Was Found in the Progression of $H$. pylori Infection-Induced Gastric Pathologies. Types of strains, host gene polymorphism, and local immune microenvironment are involved in the outcome of the disease. H. pylori has been known to induce a particular local and systemic immunity. In order to clarify the dynamic regulation of immune response induced by $H$. pylori, an overview of cytokines was conducted, and we found a discrepant cytokine profile in the $\mathrm{H}$. pylori ${ }^{+}$chronic atrophic gastritis (CAG) or gastric cancer (GC) individuals, when compared to the healthy volunteers (NGM) (unpublished data). IFN- $\gamma$, representative of type 1 immune response, decreased in CAG and GC. On the contrary, the type 2 cytokines, IL- 4 and IL-5, were stimulated in CAG and GC. In other words, an inhibited type 1 immunity and a relatively prevailed type 2 immunity were found in the microenvironments of $\mathrm{H}$. pylori ${ }^{+}$persistent chronic atrophic gastritis and gastric carcinoma.

In order to validate this assumption, fresh blood samples were collected from clinical patients and healthy volunteers. Consistent with cytokine microarray, plasma IFN- $\gamma$ concentration decreased in a time course manner in distinct $H$. pylori-involved cancerous checkpoints compared to that of plasmas from normal individuals. The type 2 cytokines, including IL-4, IL-5, and IL-13, were slightly increased but not significantly. However, Th1/Th2 balance was disturbed, 


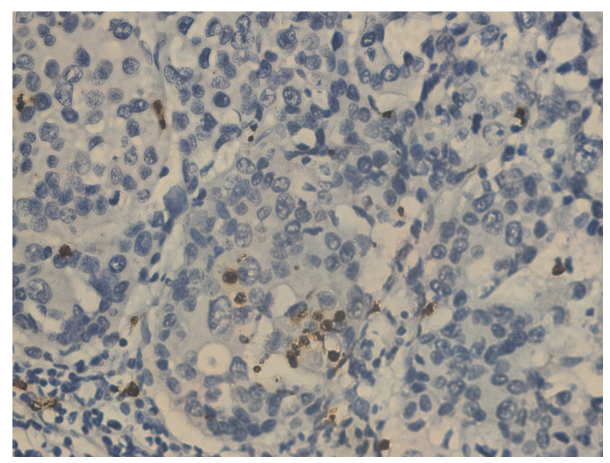

(a)

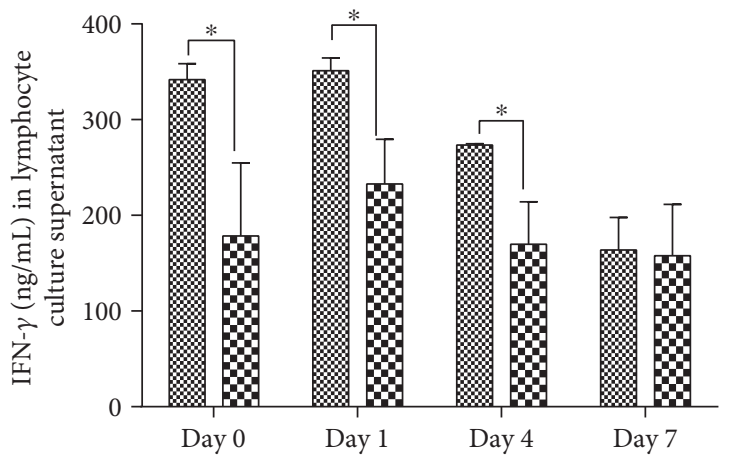

\% $\mathrm{Hp}^{-}$

$\mathbf{B} \mathrm{Hp}^{+}$

(c)

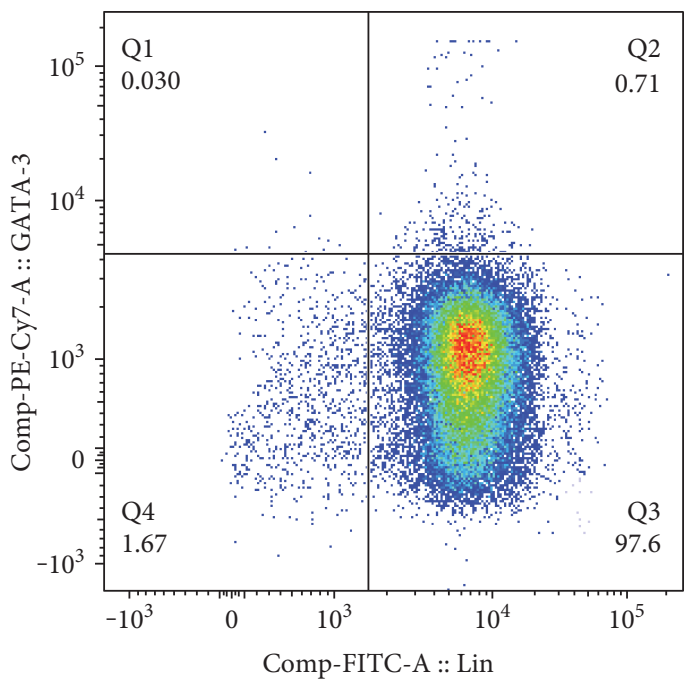

(e)

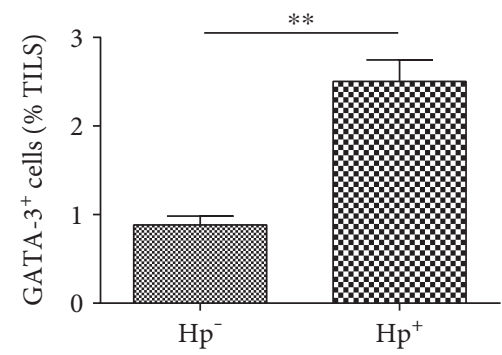

(g)

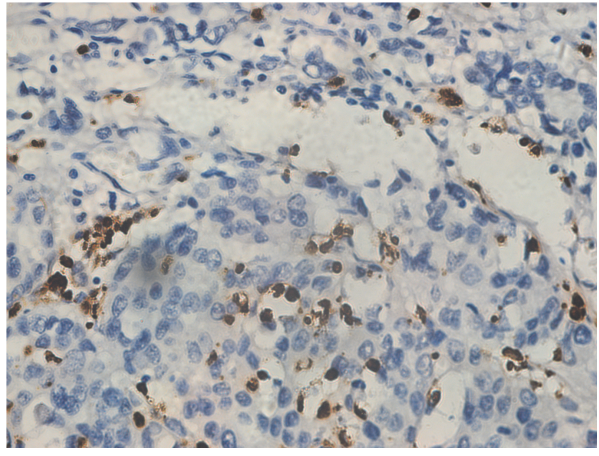

(b)

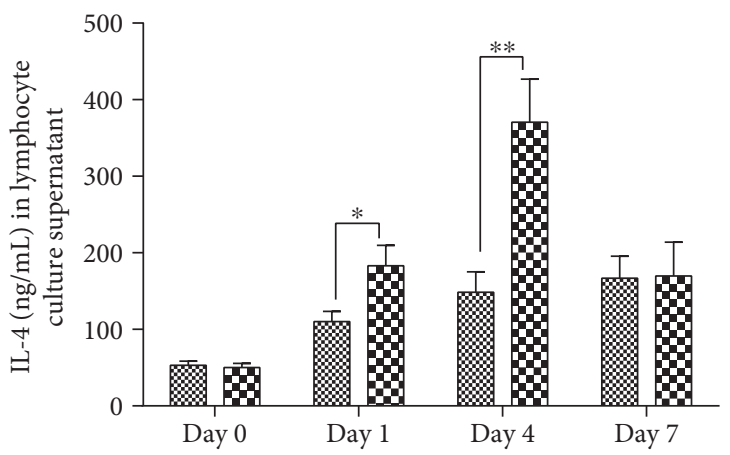

ख⿰ $\mathrm{Hp}^{-}$

$8 \mathrm{Hp}^{+}$

(d)

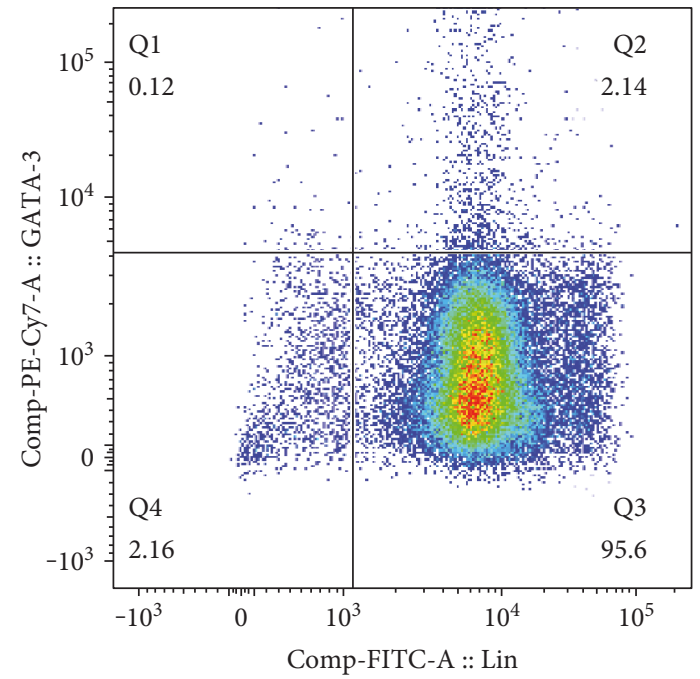

(f)

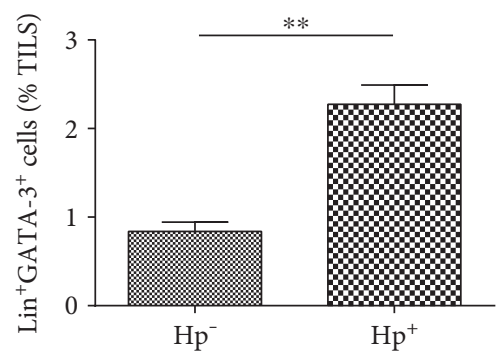

(h)

Figure 3: Continued. 


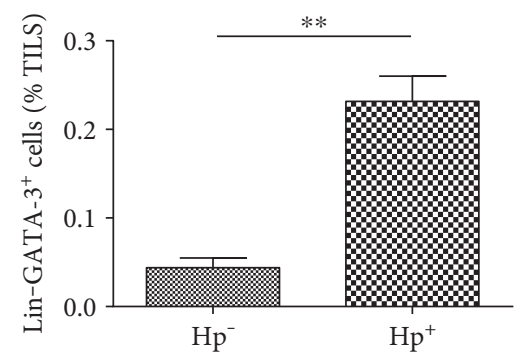

(i)

FIGURE 3: GATA-3 was enhanced in lymphocytes isolated from $H$. pylori $i^{+}$gastric cancer tissues, which was responsible for the skewed type 2 immune response. As shown in the immunohistochemical staining, when compared to the $H$. pylori $i^{-}$gastric cancer tissues (a), GATA-3 expression was significantly upregulated in the interstitial tissues of $H$. pylori $i^{+}$gastric cancer tissues (b). Moreover, the GATA- $3^{+}$cell indicated a morphological characteristic of lymphocyte. (c, d) Tumor-infiltrating lymphocytes from $\mathrm{H}_{\text {. pylori }}{ }^{+}$gastric cancer tissues $\left(\mathrm{Hp}^{+}\right)$ showed a stronger secretion of IL- 4 but a weaker secretion of IFN- $\gamma$, when compared to those from $H$. pylori gastric cancer tissues $\left(\mathrm{Hp}^{-}\right)$. (e-i) After preparation of mononuclear cells from gastric tissues, GATA- $3^{+}$population was found to increase in $H$. pylori $i^{+}$gastric cancer tissues by flow cytometry. Moreover, Lin $^{-}$GATA $-3^{+}$population and $\operatorname{Lin}^{+}$GATA- $3^{+}$population were increased in cells from $H$. pylori ${ }^{+}$ gastric cancer tissues, respectively. ${ }^{*} p<0.05,{ }^{* *} p<0.01$.

when we compared them in a ratio of IFN- $\gamma /$ type 2 cytokines, including IL-4, IL-5, or IL-13, respectively (Figures 1(a), 1(b), and 1(c)). Moreover, as displayed in Figures 1(d), 1(e), 1(f), and $1(\mathrm{~g})$, RT-PCR revealed that IL-4, IL-5, and IL-13 mRNA expressions of PBMC were gradually increased from normal to $H$. pylori ${ }^{+}$GC-derived PBMCs, which was also significant when compared to their $H$. pylori counterparts. However, IFN- $\gamma$ mRNA expression was inhibited in the progression of $H$. pylori-associated GC. These results suggested that an impaired type 1 immune response and a potential enhanced type 2 immune response were induced in the progression of H. pylori-associated gastric diseases. In order to further confirm this, we have also established an $H$. pylori infection model in vitro and in vivo. Similarly, we found that type 1 cytokine, IFN- $\gamma$, was inhibited and type 2 cytokines, like IL4 , IL-5, and IL-13, were augmented or stayed undisturbed in the H. pylori infection group in vitro and in vivo (Figure 2).

3.2. GATA-3-Positive Lymphocytes Were Increased in $H$. pylori-Induced Gastric Diseases. GATA-3 has been demonstrated to be involved in the progression of $H$. pylori-associated gastric cancer in our previous findings, which was explained by the decreased $\mathrm{Cx} 32$ and $\mathrm{Cx} 43$ expression and disordered gap junction in vitro and in vivo [12]. As a critical transcript factor, GATA-3 was also known to play a decisive role in type 2 immunity, which might partly explain the bias in the chronic H. pylori infection. Accordingly, we have detected GATA-3 in gastric cancer tissues and found that GATA-3 was strongly upregulated in the mesenchyme of H. pylori ${ }^{+}$gastric cancer tissues, while the GATA-3-positive cells were nearly much less in the H. pylori ${ }^{-}$gastric cancer tissues or paired normal gastric tissues (Figures 3(a) and 3(b)). More interestingly, lymphocyte populations derived from different gastric cancerous tissues displayed distinct function. After culture in vitro for a week, lymphocytes isolated from H. pylori-infected gastric cancer tissues $\left(\mathrm{Hp}^{+}\right)$displayed a vigorous ability to secrete IL-4 and an impaired function of IFN- $\gamma$ secretion, when compared to those isolated from the H. pylori-uninfected individuals $\left(\mathrm{Hp}^{-}\right)$(Figures $3(\mathrm{c})$ and 3(d)). From the morphological point of view, we inferred that GATA $-3^{+}$cells were mainly lymphocytes. We have also proved that the increased GATA- $3^{+}$cells were mainly distributed in the lymphocyte population freshly isolated from the $H$. pylori-infected gastric cancerous tissues (Figures 3(e) and 3(f)). Moreover, overexpression of GATA-3 mRNA was not only found in the PBMCs along the progression of $H$. pylori infection-induced gastric disease but also presented in the H. pylori ${ }^{+}$GC tissues and their derived mononuclear cells, and weaker expression was displayed in the H. pylori ${ }^{-}$ gastric cancer tissues or the lymphocytes (Supplementary Figure 1A-B available online at https://doi.org/10.1155/ 2017/4927964).

\subsection{Lin $^{-}$GATA $-3^{+}$Population and $\operatorname{Lin}^{+}$GATA-3 $3^{+}$Population} Were Increased in H. pylori Infection. GATA-3, known as a critical transcript factor for both ILC2s and Th2 cells, was found to be increased in $H$. pylori-infected gastric cancer tissues. In order to clarify how the definite population plays a role in $\mathrm{H}$. pylori-induced immune response, we tried to identify them by flow cytometry. As the expression of GATA-3 was mainly distributed in Th2 cells, recently, GATA-3 was also found to be highly expressed in ILC2s. Interestingly, we found that $\mathrm{Lin}^{-}$GATA $-3^{+}$and $\mathrm{Lin}^{+} \mathrm{GATA}-3^{+}$population both increased in the $H$. pylori-infected individuals (Figures 3(e), 3(f), 3(g), 3(h), and 3(i)).

To further verify this, a coculture system in vitro was conducted as described before [19]. After coculture, PBMCs were detected by flow cytometry; an increase in the percentage of GATA-3-positive cells was found. Moreover, after being cocultured with $H$. pylori-infected GES-1, PBMCs displayed a much higher expression of GATA-3 translationally and transcriptionally (Supplementary Figure 1C-D). Interestingly, there was also a remarkable increase in the $\mathrm{Lin}^{-}$GATA $-3^{+}$and $\mathrm{Lin}^{+}$GATA $-3^{+}$population after coculture (Figures 4(a), 4(b), and $4(\mathrm{c}))$.

Given that ILC2s are GATA-3-expressing innate lymphocytes and other innate lymphocyte lineages (i.e., ILC1 and ILC3) expressed only weak or little GATA-3. Based on 

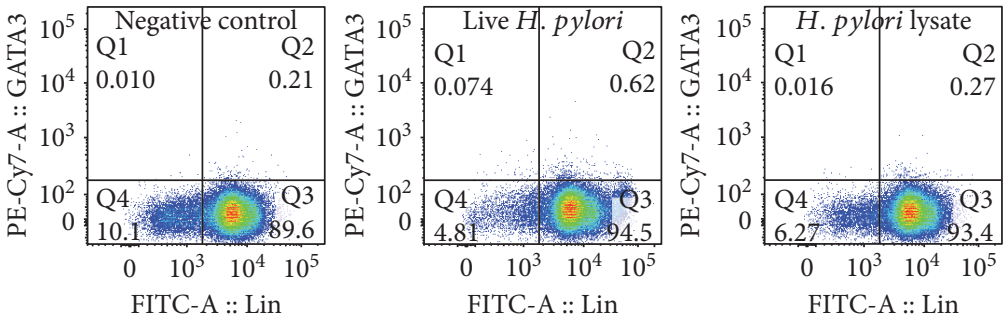

(a)

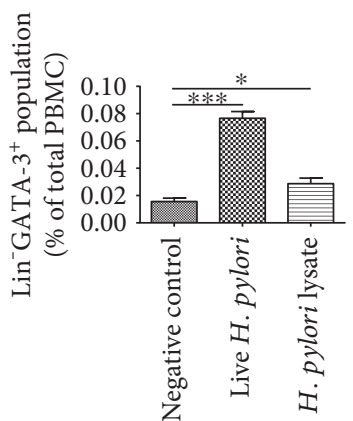

(b)
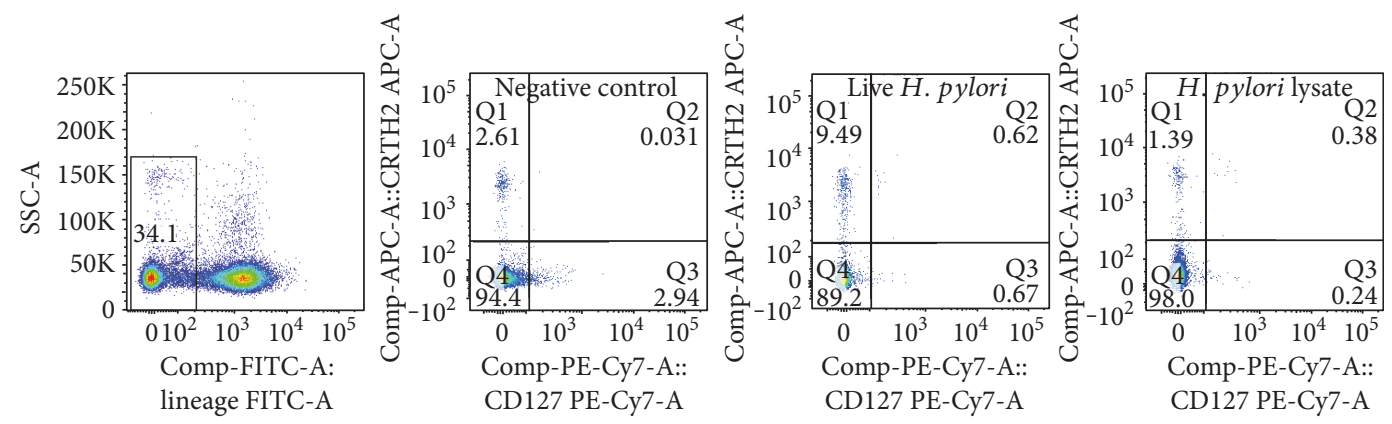

(d)

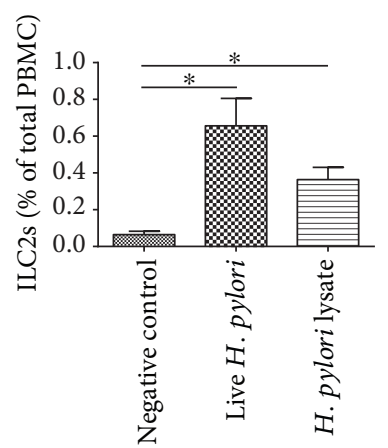

(e)

Figure 4: GATA- $3^{+}$and Lin $^{-}$GATA $-3^{+}$populations were found to increase after $H$. pylori infection in vitro. A coculture system was conducted as described before. (a) After coculture with $H$. pylori-infected GES-1, PBMCs were detected by flow cytometry. GATA- $3^{+}$ population was found to increase after live $H$. pylori infection. (b, c) Moreover, Lin $^{-}$GATA $-3^{+}$and Lin ${ }^{+}$GATA- $3^{-}$populations were both found increased. (d, e) ILC2s were also proved to increase after live $H$. pylori infection. ${ }^{*} p<0.05,{ }^{* * *} p<0.001$.

our above findings, it was logical to deduce that ILC2 population in PBMCs was increased after H. pylori infection. To verify this, ILC2s, defined as $\mathrm{Lin}^{-} \mathrm{CD} 127^{+} \mathrm{CRTH} 2^{+}$, were detected by flow cytometry. As shown in Figures 4(d) and 4(e), ILC2, one of the innate immunity members, was involved in $H$. pylori infection-induced skewed type 2 immune response.
3.4. ILC2s Were Found to Be Increased in Clinical $H$. pylori-Infected Individuals. According to the above results, Lin $^{-}$GATA $-3^{+}$and Lin $^{+}$GATA- ${ }^{+}$cells, which indicated a phenotype of ILC2 and Th2, respectively, increased significantly after $H$. pylori infection. As a member of natural innate immunity, ILC2 was demonstrated to play a role in defending microbial pathogens, including virus, parasites, and 

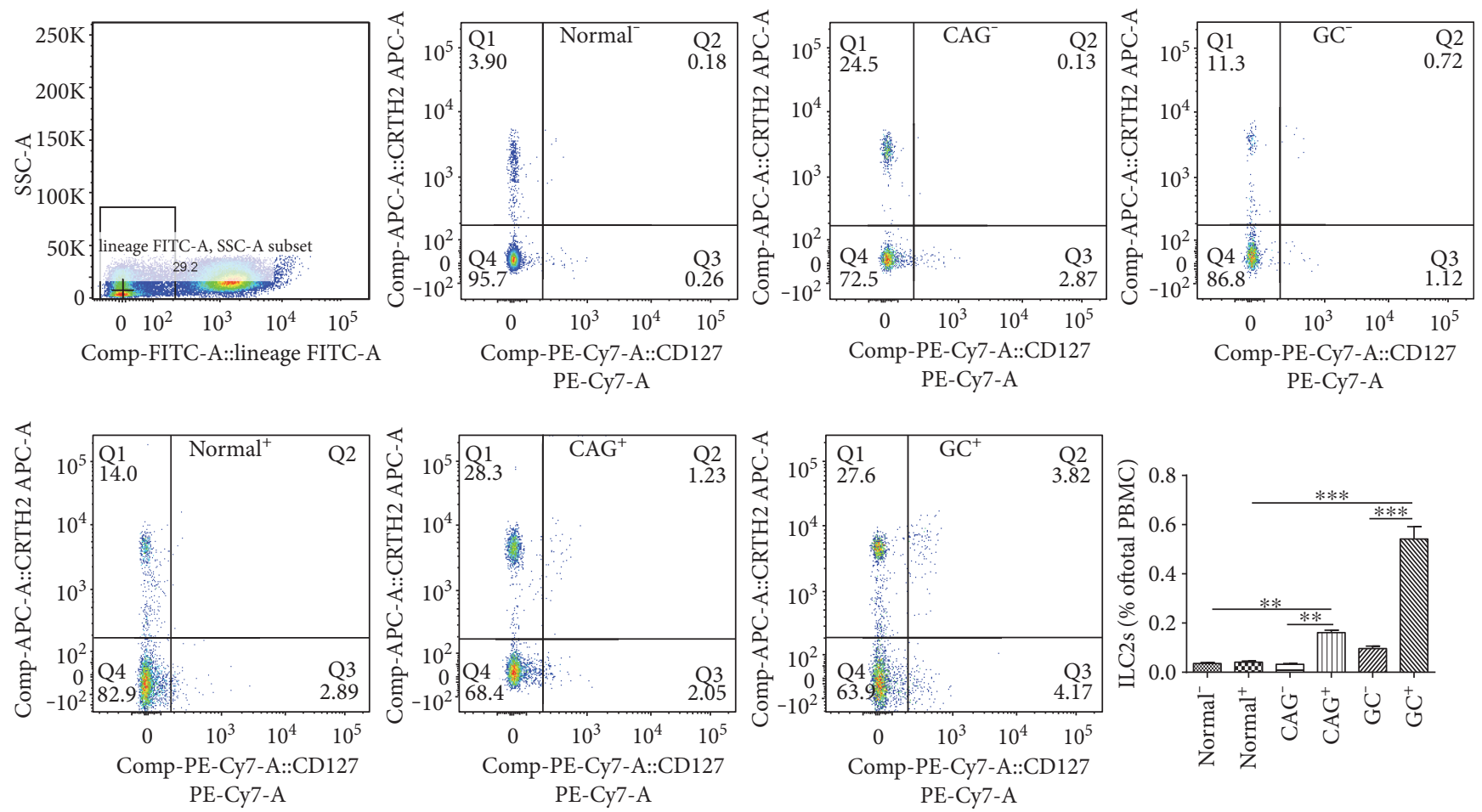

FIgure 5: ILC2s, defined as $\mathrm{Lin}^{-} \mathrm{CRTH} 2^{+} \mathrm{CD} 127^{+}$, were found to increase in $\mathrm{H}$. pylori ${ }^{+}$chronic gastritis $\left(\mathrm{CAG}^{+}\right)$and gastric cancer $\left(\mathrm{GC}^{+}\right)$individuals, when compared to normal individuals. However, there was no difference in the $H$. pylori ${ }^{-}$counterparts. ${ }^{* *} p<0.01$, ${ }^{* * *} p<0.001$.

bacteria. Moreover, ILC2s were an important source of type 2 immune response cytokines and played a vital role in activating and maintaining Th2 immunity. As a result, it was reasonable to deduce that ILC2s were a possible main squeeze for the prevailing type 2 immunity, especially with the enhanced GATA-3 expression. Therefore, ILC2 $\left(\mathrm{Lin}^{-} \mathrm{CRTH} 2^{+} \mathrm{CD} 127^{+}\right.$) count was analyzed by flow cytometry. As expected, ILC2s were found to increase in the $H$. pylori infection group, especially displaying a gradual increase along the disease progression, when compared to the corresponding control group, which was free of $H$. pylori involvement, and healthy volunteers (Figure 5).

3.5. An Enhanced GATA-3 Expression and Increased ILC2s Were Also Found with H. pylori Infection In Vivo. In order to verify the role of GATA-3 and/or ILC2s played in the dominant type 2 immune response induced by $H$. pylori, we have established a series of mouse models by giving gavages of different strains of $H$. pylori. As described above, the enhanced type 2 immune response and inhibited type 1 immune response were also observed in the microenvironment of $H$. pylori-infected C57B/L6 in comparison with that of control groups (Figure 2). ILC2s were also found to be increased in the H. pylori-infected group (Figure 6). Moreover, East Asian-type H. pylori strain stirred up the most powerful immune response. The mice displayed a distinct pattern of GATA-3 mRNA expression in splenocytes, among them, East Asian-type $H$. pylori was shown to cause the most significant transformation, when compared to the control group given a comparable gavages of PBS (Supplementary Figure 1E).

\section{Discussion}

In a country with high $H$. pylori infection rates, over half of Chinese people are infected with this gram-negative bacilli; however, clinical outcomes vary from different hosts and strains. About $20 \%$ of infected individuals develop $H$. pylori-associated gastric disease, while majority remain asymptomatic; immune response caused by reciprocal interaction displays a crucial role in these different outcomes $[20,21]$. Abundant evidence demonstrates that the pathogenesis of lesions originated from the infected gastric mucosal epithelium is mostly attributed to the $\mathrm{T}$ cell-driven immune responses $[3,8,22,23]$. As a gastric bacterial pathogen, $H$. pylori causes defensive response immediately upon its adhesion and invasion, "alarmins" will be released from the gastric mucosal epithelium, and lymphocytes are recruited and activated, hence promoting their special cellular immunity and humoral immunity [24].

Both of the recruitment of neutrophils and mast cells contribute critically to the effector phase of $H$. pylori clearance through their effective cytokines [25]. Even so, chronic and persistent infection of $H$. pylori has been proved to be the most frequent clinical status. Plentiful evidence suggests that specific $\mathrm{T}$ cell subsets and their distinctive cytokine 

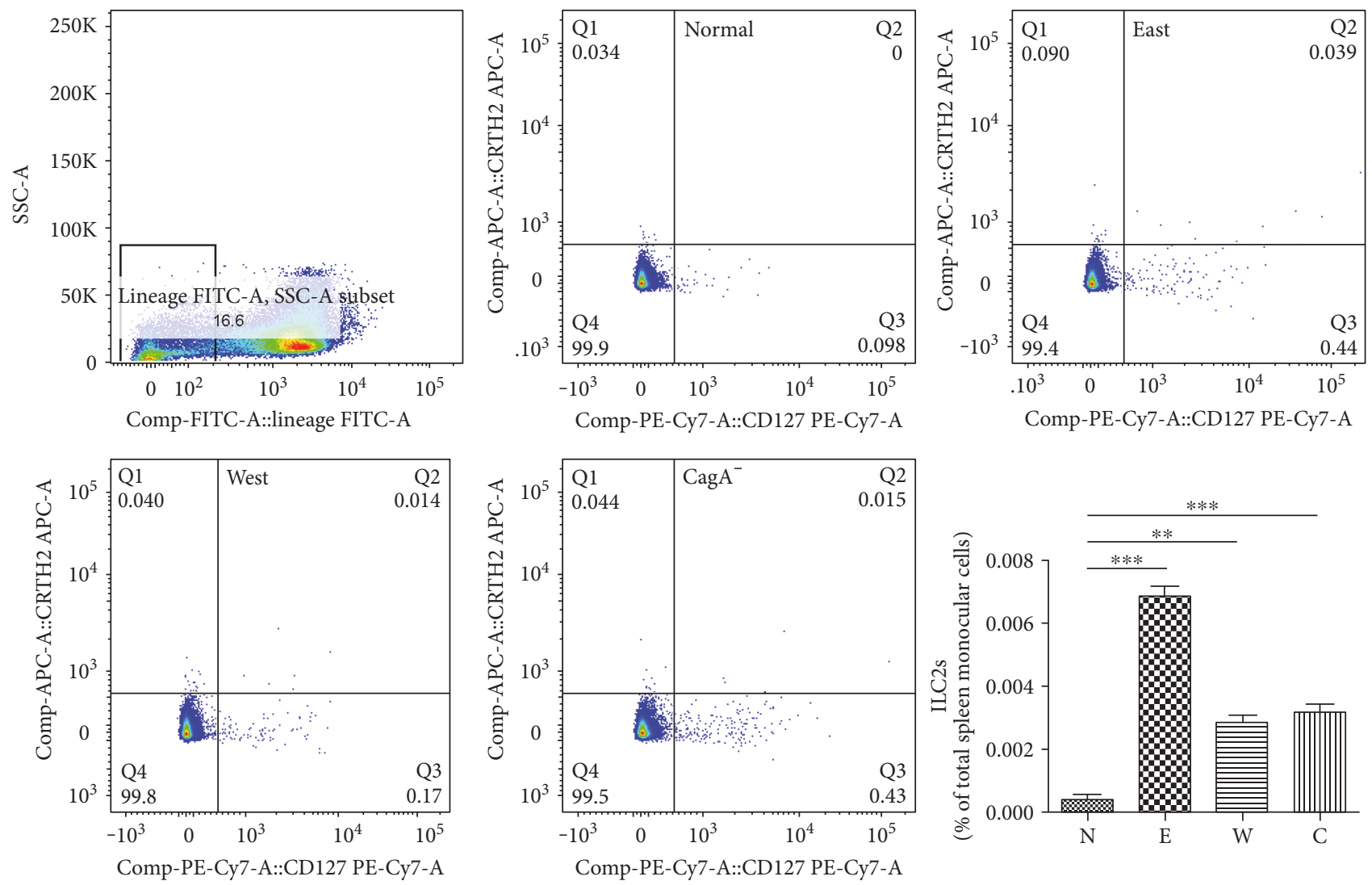

Figure 6: An increased ILC2 $\left(\mathrm{Lin}^{-} \mathrm{CRTH} 2^{+} \mathrm{CD} 127^{+}\right)$proportion was found in vivo. After gavages of different $H$. pylori strains, ILC2 populations in mice were found to increase, especially in the group treated with the East Asian type (E). The Western-type (W) and $\mathrm{CagA}^{-}$(C) H. pylori also promoted a slender enhancement of ILC2 at a much lower extent. ${ }^{* *} p<0.01,{ }^{* * *} p<0.001$.

profiles contribute to the control of $H$. pylori infections on the one hand and to the associated gradual gastric plastic pathology on the other. Generally speaking, upon microorganism infection, $H$. pylori neutrophil activation protein and cytotoxin-associated gene A (CagA) expressed on the bacterial surface will stimulate macrophages, whose activated cytokines are secreted, including IL-12 and IL-23, which are potent stimuli for type 1 immune response [26]. A preferential activation of Th1 response has also been suggested in different animal models in the early phase of $H$. pylori infection, such as mice, monkeys, and dogs experimentally infected with $H$. pylori [27-29]. Simultaneously, macrophages, Treg, or Th2 were activated to relieve the inflammatory activity, especially in $H$. pylori strains carrying the cag pathogenicity island, which confers an increased risk of atrophic lesions and carcinogenesis in Chinese carriers [30-32]. Furthermore, chronic inflammatory and negligent microenvironment of the stomach induced by $H$. pylori is thus usually promoted.

Type 2 immunity which consists of responses dominated by the cardinal type 2 cytokines has been demonstrated to be responsible for $H$. pylori-associated chronic inflammation, especially for the carcinogenesis and immune escape of gastric cancer [33]. According to our results, ILC2s, one of the important sources of type 2 cytokines, might be a novel candidate actor and promoter for preferred type 2 immunity in H. pylori infection. Firstly, GATA-3 expression is upregulated by infection of $H$. pylori in vitro and in vivo. Secondly, the proportion of ILC2s is significantly increased in the $H$. pylori-infected patients and $H$. pylori infection models in vitro and in vivo, which accords with the findings of Bie et al. that ILC2 contributed to immunosuppressive microenvironment in the Chinese gastric cancer patients, of which, most are H. pylori positive [34]. More importantly, in many situations, ILC2s and Th2 cells collaborate during type 2 immune responses [35-38].

In addition to their established role in innate immunity, ILC2s function to promote Th2 adaptive immunity. Firstly, ILC2s can enhance $\mathrm{CD} 4^{+} \mathrm{T}$ cell proliferation in vitro [36]. Secondly, ILC2s can activate and maintain the production of type 2 cytokines from Th2. As an initiator, IL-4 promotes the Th2 differentiation. IL-4 produced initially by ILC2s can activate Th2 cells, initiate, and/or enhance the capacity of the IL-4 production [39]. More importantly, the interaction between ILC2s and $\mathrm{CD}^{+} \mathrm{T}$ cells involves the costimulatory molecule OX40L and the cytokine IL-4, which are mainly derived from ILC2s [37]. DCs and/or macrophages also participate in ILC2-induced Th2 differentiation. Moreover, Th cells also contribute to ILC2 activation. MHC class II expressed on ILC2s will activate T cells to produce IL-2, which will act back on ILC2s to produce more IL- 4 and activate the Th2 consistently $[35,36,40]$. IL- 4 produced by preliminary cells (including ILC2s and developing Th2 cells) 
may activate Th2 cells in a paracrine and/or autocrine manner in return. Therefore, a regulatory feedback mechanism can be concluded as a fundamental principle for the interaction between ILC2s and Th2 cell differentiation [41]. The two pathways could be concluded as ILC2/IL-4/ GATA-3/Th2/IL-4 and CD4 ${ }^{+}$T/IL-2/ILC2/IL-4/Th2. However, whether direct ILC2 and T cell interaction is critical for initiating and promoting Th2 cell differentiation or this interaction mainly reflects collaborative relationship of ILC2s and Th2 cells at the effector stage in H. pylori infection requires further investigation.

GATA-3 also plays an important role in both Th2 and ILC2 development and interaction. Hoyler et al. have demonstrated that GATA-3, a critical transcription factor for Th2 cells, is also an important regulator for ILC2 lineage specification and maintenance by using excellent genetic and cellular approaches [42]. Mjosberg et al. have proved that GATA-3 is essential for the production of type 2 cytokines (e.g., IL-13, IL-5, and IL-4) by human ILC2s and also depicted the signaling pathways involved in regulating ILC2s' function [43]. Moreover, persistent expression of GATA-3 is important for the maintenance of a mature phenotype and cytokine profiles. Temporal deletion of GATA-3 affects the ILC2s' progenitor pool in the bone marrow and will also inhibit the Th2 differentiation in the peripheral immune system [14]. Though not validated in the present study, it is logical to hypothesize that overexpression of GATA-3 in lymphocytes is a critical molecular mechanism for increased ILC2s and Th2 cells in H. pylori infectionassociated gastric disease.

In conclusion, our present study showed that there is a type 2 immunity dominant in the development of $H$. pylori infection-associated gastric disease. Activation of ILC2s upon H. pylori infection might be responsible for the dominant type 2 immune response. Furthermore, increased expression of GATA-3 induced by $H$. pylori invasion might be a possible mechanism explanation for the skewed type 2 immune responses, and further validation is still warranted.

\section{Conflicts of Interest}

The authors declare that they have no conflicts of interest.

\section{Acknowledgments}

This work was supported by grants from the National Natural Scientific Foundation of China (no. 81570509).

\section{References}

[1] P. Correa, "Helicobacter pylori and gastric carcinogenesis," The American Journal of Surgical Pathology, vol. 19, Supplement 1, pp. S37-S43, 1995.

[2] W. Chen, R. Zheng, P. D. Baade et al., "Cancer statistics in China, 2015," CA: A Cancer Journal for Clinicians, vol. 66, no. 2, pp. 115-132, 2016.

[3] A. Sayi, E. Kohler, I. Hitzler et al., "The $\mathrm{CD} 4^{+} \mathrm{T}$ cell-mediated IFN- $\gamma$ response to helicobacter infection is essential for clearance and determines gastric cancer risk," Journal of Immunology, vol. 182, no. 11, pp. 7085-7101, 2009.
[4] J. J. Bearss, M. Hunter, J. L. Dankmeyer et al., "Characterization of pathogenesis of and immune response to Burkholderia pseudomallei K96243 using both inhalational and intraperitoneal infection models in $\mathrm{BALB} / \mathrm{C}$ and C57BL/6 mice," PLoS One, vol. 12, article e0172627, no. 2, 2017.

[5] K. Hirahara and T. Nakayama, "CD4 ${ }^{+}$T-cell subsets in inflammatory diseases: beyond the Th1/Th2 paradigm," International Immunology, vol. 28, no. 4, pp. 163-171, 2016.

[6] A. P. Gobert and K. T. Wilson, "The immune battle against Helicobacter pylori infection: NO offense," Trends in Microbiology, vol. 24, no. 5, pp. 366-376, 2016.

[7] A. Lamb and L. F. Chen, "Role of the Helicobacter pyloriinduced inflammatory response in the development of gastric cancer," Journal of Cellular Biochemistry, vol. 114, no. 3, pp. 491-497, 2013.

[8] I. C. Arnold, I. Hitzler, D. Engler, M. Oertli, E. M. Agger, and A. Muller, "The C-terminally encoded, MHC class II-restricted $\mathrm{T}$ cell antigenicity of the Helicobacter pylori virulence factor CagA promotes gastric preneoplasia," Journal of Immunology, vol. 186, no. 11, pp. 6165-6172, 2011.

[9] S. K. Wang, H. F. Zhu, B. S. He et al., "CagA+ H pylori infection is associated with polarization of $\mathrm{T}$ helper cell immune responses in gastric carcinogenesis," World Journal of Gastroenterology, vol. 13, no. 21, pp. 2923-2931, 2007.

[10] Z. Ren, G. Pang, R. Clancy et al., "Shift of the gastric T-cell response in gastric carcinoma," Journal of Gastroenterology and Hepatology, vol. 16, no. 21, pp. 142-148, 2001.

[11] K. Moro and S. Koyasu, "Innate lymphoid cells, possible interaction with microbiota," Seminars in Immunopathology, vol. 37, no. 1, pp. 27-37, 2015.

[12] X. Liu, K. Cao, C. Xu et al., "GATA-3 augmentation downregulates Connexin 43 in Helicobacter pylori associated gastric carcinogenesis," Cancer Biology \& Therapy, vol. 16, no. 6, pp. 987-996, 2015.

[13] I. Tindemans, N. Serafini, J. P. Di Santo, and R. W. Hendriks, "GATA-3 function in innate and adaptive immunity," Immunity, vol. 41, no. 2, pp. 191-206, 2014.

[14] L. Zhou, "Striking similarity: GATA-3 regulates ILC2 and Th2 cells,” Immunity, vol. 37, no. 4, pp. 589-591, 2012.

[15] K. C. De Grove, S. Provoost, R. W. Hendriks et al., "Dysregulation of type 2 innate lymphoid cells and TH2 cells impairs pollutant-induced allergic airway responses," The Journal of Allergy and Clinical Immunology, vol. 139, no. 1, article e244, pp. 246-257, 2017.

[16] T. Y. Halim, Y. Y. Hwang, S. T. Scanlon et al., "Group 2 innate lymphoid cells license dendritic cells to potentiate memory TH2 cell responses," Nature Immunology, vol. 17, no. 1, pp. 57-64, 2016.

[17] V. S. Pelly, Y. Kannan, S. M. Coomes et al., "IL-4-producing ILC2s are required for the differentiation of $\mathrm{T}_{\mathrm{H}} 2$ cells following Heligmosomoides polygyrus infection," Mucosal Immunology, vol. 9, no. 6, pp. 1407-1417, 2016.

[18] B. Roediger and W. Weninger, "Group 2 innate lymphoid cells in the regulation of immune responses," Advances in Immunology, vol. 125, pp. 111-154, 2015.

[19] R. Lin, H. Ma, Z. Ding et al., "Bone marrow-derived mesenchymal stem cells favor the immunosuppressive T cells skewing in a Helicobacter pylori model of gastric cancer," Stem Cells and Development, vol. 22, pp. 2836-2848, 2013. 
[20] A. Mueller, A. Sayi, and I. Hitzler, "Protective and pathogenic functions of T-cells are inseparable during the Helicobacter-host interaction," Discovery Medicine, vol. 8, pp. 68-73, 2009.

[21] J. Parsonnet, S. Hansen, L. Rodriguez et al., "Helicobacter pylori infection and gastric lymphoma," The New England Journal of Medicine, vol. 330, pp. 1267-1271, 1994.

[22] I. C. Arnold, J. Y. Lee, M. R. Amieva et al., “Tolerance rather than immunity protects from Helicobacter pylori-induced gastric preneoplasia," Gastroenterology, vol. 140, pp. 199209, 2011.

[23] A. Sayi, E. Kohler, I. M. Toller et al., "TLR-2-activated B cells suppress Helicobacter-induced preneoplastic gastric immunopathology by inducing T regulatory-1 cells," Journal of Immunology, vol. 186, pp. 878-890, 2011.

[24] H. Hammad and B. N. Lambrecht, "Barrier epithelial cells and the control of type 2 immunity," Immunity, vol. 43, pp. 29-40, 2015.

[25] I. Hitzler, M. Oertli, B. Becher, E. M. Agger, and A. Muller, "Dendritic cells prevent rather than promote immunity conferred by a helicobacter vaccine using a mycobacterial adjuvant," Gastroenterology, vol. 141, article e181, pp. 186196, 196, 2011.

[26] G. Del Prete, L. Chiumiento, A. Amedei et al., "Immunosuppression of $\mathrm{T}_{\mathrm{H}} 2$ responses in Trichinella spiralis infection by Helicobacter pylori neutrophil-activating protein," The Journal of Allergy and Clinical Immunology, vol. 122, article e905, pp. 908-913, 2008.

[27] L. E. Smythies, K. B. Waites, J. R. Lindsey, P. R. Harris, P. Ghiara, and P. D. Smith, "Helicobacter pylori-induced mucosal inflammation is Th1 mediated and exacerbated in IL-4, but not IFN-gamma, gene-deficient mice," Journal of Immunology, vol. 165, pp. 1022-1029, 2000.

[28] G. Rossi, D. Fortuna, L. Pancotto et al., "Immunohistochemical study of lymphocyte populations infiltrating the gastric mucosa of beagle dogs experimentally infected with Helicobacter pylori," Infection and Immunity, vol. 68, pp. 4769-4772, 2000.

[29] J. J. Mattapallil, S. Dandekar, D. R. Canfield, and J. V. Solnick, "A predominant Th1 type of immune response is induced early during acute Helicobacter pylori infection in rhesus macaques," Gastroenterology, vol. 118, pp. 307-315, 2000.

[30] J. H. Gil, J. W. Seo, M. S. Cho, J. H. Ahn, and H. Y. Sung, "Role of Treg and TH17 cells of the gastric mucosa in children with Helicobacter pylori gastritis," Journal of Pediatric Gastroenterology and Nutrition, vol. 58, pp. 245-251, 2014.

[31] P. R. Harris, S. W. Wright, C. Serrano et al., "Helicobacter pylori gastritis in children is associated with a regulatory $\mathrm{T}$ cell response," Gastroenterology, vol. 134, pp. 491-499, 2008.

[32] M. Koch, H. J. Mollenkopf, and T. F. Meyer, "Macrophages recognize the Helicobacter pylori type IV secretion system in the absence of toll-like receptor signalling," Cellular Microbiology, vol. 18, pp. 137-147, 2016.

[33] P. G. Fallon, H. E. Jolin, P. Smith et al., "IL-4 induces characteristic Th2 responses even in the combined absence of IL-5, IL-9, and IL-13," Immunity, vol. 17, pp. 7-17, 2002.

[34] Q. Bie, P. Zhang, Z. Su et al., "Polarization of ILC2s in peripheral blood might contribute to immunosuppressive microenvironment in patients with gastric cancer," Journal of Immunology Research, vol. 2014, Article ID 923135, 10 pages, 2014.
[35] C. J. Oliphant, Y. Y. Hwang, J. A. Walker et al., "MHCII-mediated dialog between group 2 innate lymphoid cells and $\mathrm{CD} 4^{+} \mathrm{T}$ cells potentiates type 2 immunity and promotes parasitic helminth expulsion," Immunity, vol. 41, pp. 283-295, 2014.

[36] A. S. Mirchandani, A. G. Besnard, E. Yip et al., "Type 2 innate lymphoid cells drive $\mathrm{CD}^{+}$Th2 cell responses," Journal of Immunology, vol. 192, pp. 2442-2448, 2014.

[37] L. Y. Drake, K. Iijima, and H. Kita, "Group 2 innate lymphoid cells and $\mathrm{CD}^{+} \mathrm{T}$ cells cooperate to mediate type 2 immune response in mice," Allergy, vol. 69, pp. 1300-1307, 2014.

[38] T. Y. Halim, C. A. Steer, L. Matha et al., "Group 2 innate lymphoid cells are critical for the initiation of adaptive T helper 2 cell-mediated allergic lung inflammation," Immunity, vol. 40, pp. 425-435, 2014.

[39] J. Zhu, "T helper 2 (Th2) cell differentiation, type 2 innate lymphoid cell (ILC2) development and regulation of interleukin-4 (IL-4) and IL-13 production," Cytokine, vol. 75, no. 1, pp. 1424, 2015.

[40] F. Van Gool, A. B. Molofsky, M. M. Morar et al., "Interleukin5-producing group 2 innate lymphoid cells control eosinophilia induced by interleukin-2 therapy," Blood, vol. 124, no. 24, pp. 3572-3576, 2014.

[41] J. Zhu, H. Yamane, and W. E. Paul, "Differentiation of effector CD4 T cell populations," Annual Review of Immunology, vol. 28, pp. 445-489, 2010.

[42] T. Hoyler, C. S. Klose, A. Souabni et al., "The transcription factor GATA-3 controls cell fate and maintenance of type 2 innate lymphoid cells," Immunity, vol. 37, no. 4, pp. 634648, 2012.

[43] J. Mjosberg, J. Bernink, K. Golebski et al., "The transcription factor GATA3 is essential for the function of human type 2 innate lymphoid cells," Immunity, vol. 37, no. 4, pp. 649659, 2012. 


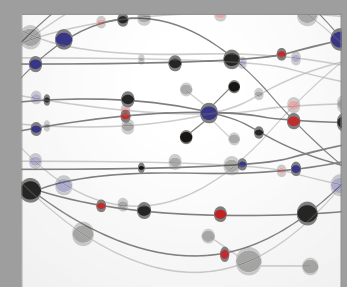

The Scientific World Journal
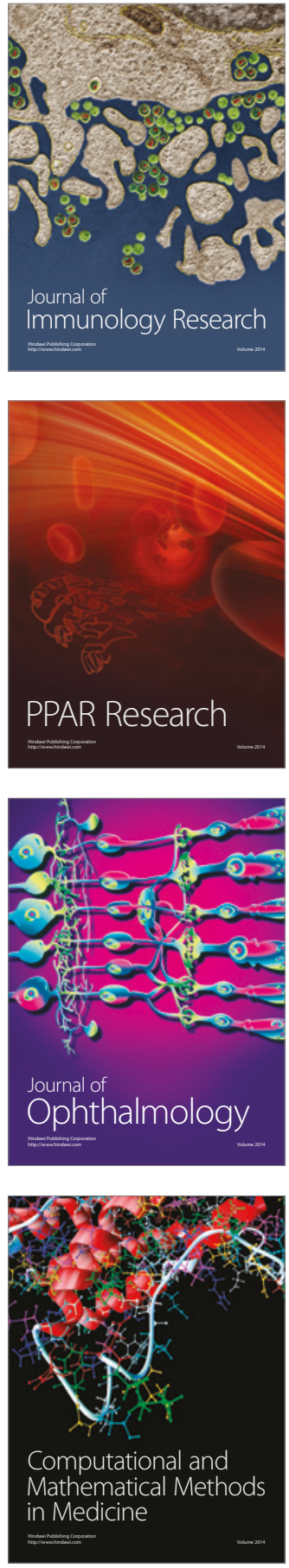

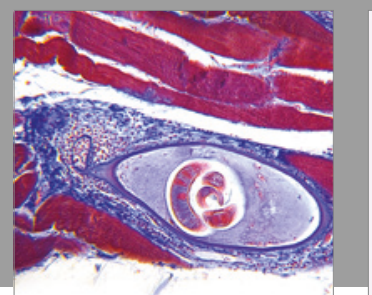

Gastroenterology Research and Practice
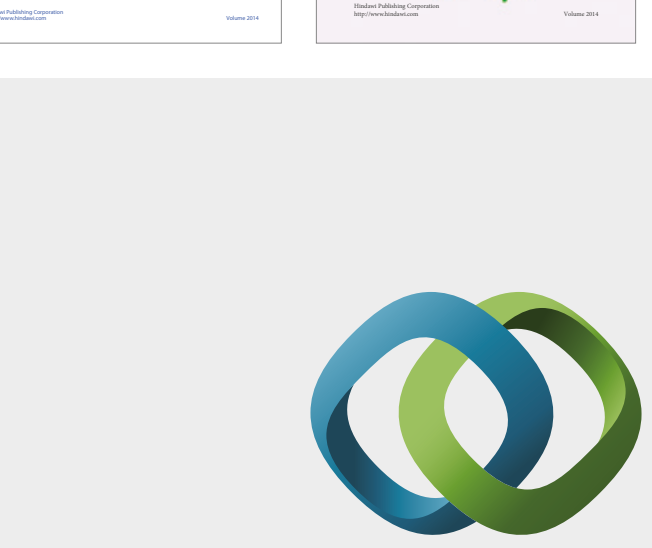

\section{Hindawi}

Submit your manuscripts at

https://www.hindawi.com
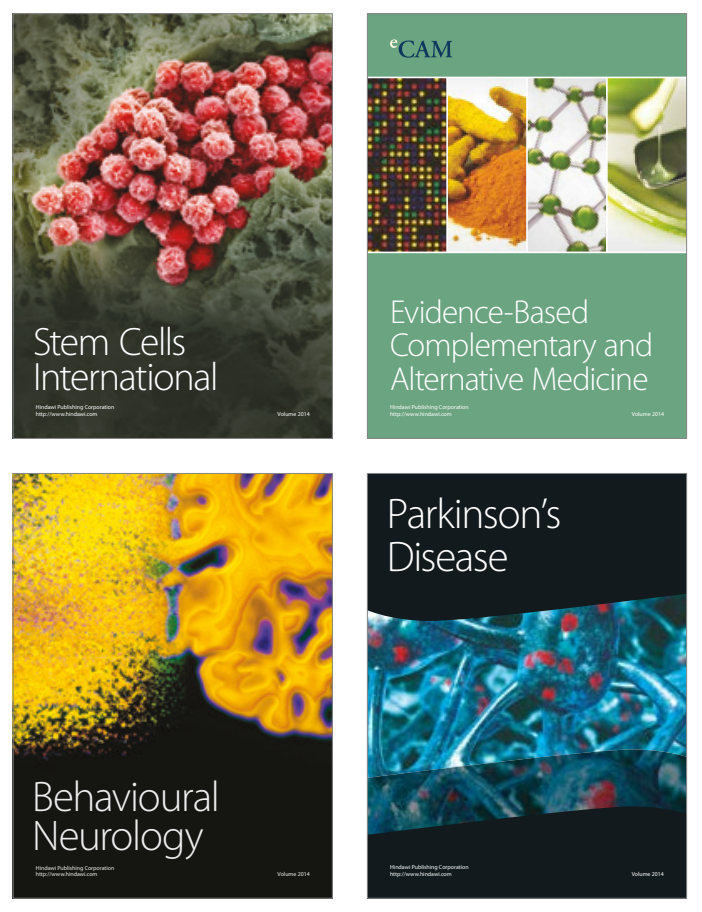
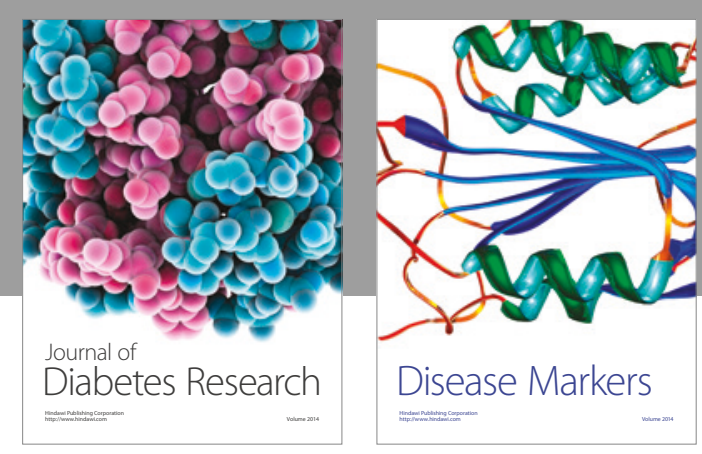

Disease Markers
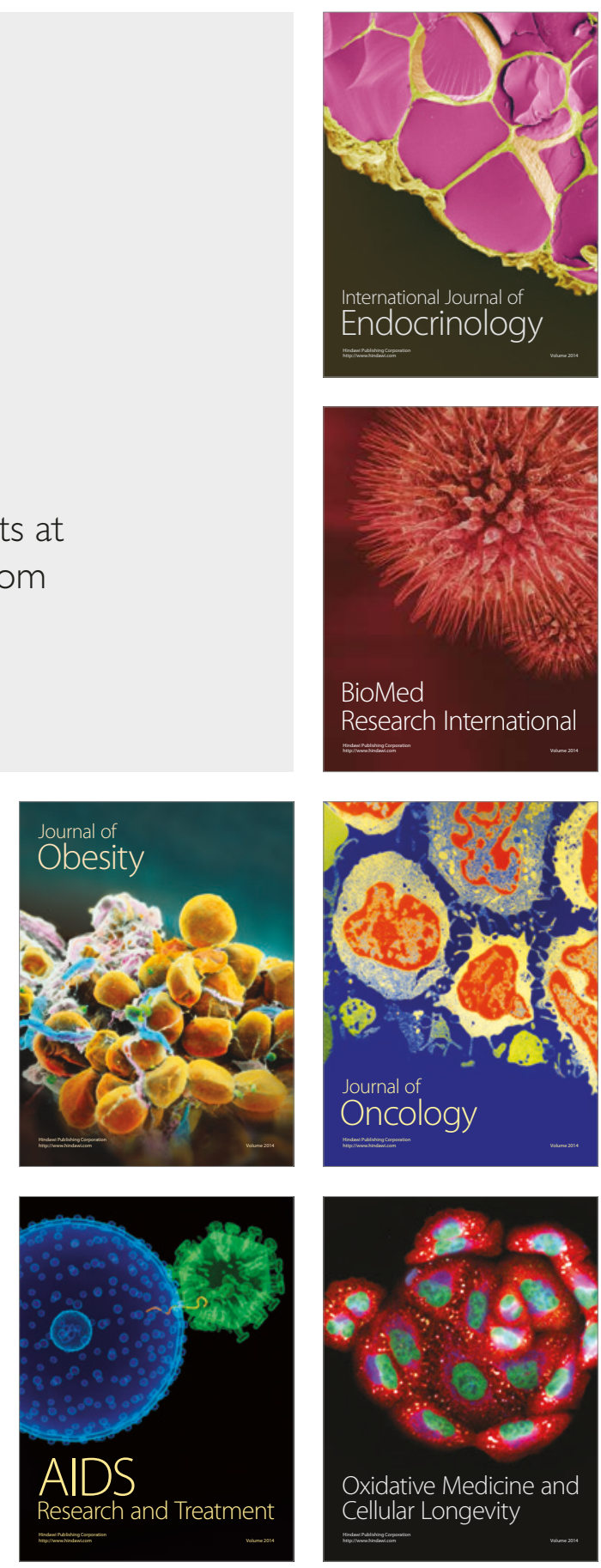